\title{
Students' perceptions of Blackboard and Moodle in a Portuguese university
}

\section{Ana Carvalho, Nelson Areal and Joaquim Silva}

Ana Carvalho is an assistant professor in the Management Department at the University of Minho. Her current research interests include management education, strategic human resource management and nonprofit organisations. Nelson Areal is an assistant professor in the Management Department at the University of Minho. His current research interests are management education, volatility forecasting and measurement and social responsible investments. Joaquim Silva is a guest lecturer in the Management Department at the University of Minho, and his research interests cover management education, relationship marketing and service dominant logic in marketing. Address for correspondence: Assistant Professor Ana Carvalho, Management Department, University of Minho, Escola de Economia e Gestão, 4710-057 Braga, Portugal; email: anac@eeg.uminho.pt

\begin{abstract}
The use of learning management systems (LMS) has grown considerably in universities around the world. The University of Minho (UM) has pioneered in this area in Portugal, adopting Blackboard as its official LMS. Moodle is also used in UM in scattered initiatives, allowing for interesting comparisons.

Previous studies comparing Blackboard and Moodle have been confined to limited samples and focused on students' perceptions only. In this paper, we also try to relate those perceptions to the impact of the LMSs on student level of engagement.

We assess the extent and depth of use of the two LMSs, presenting the results of a study of students' perceptions and experience with both Blackboard and Moodle. Unlike previous studies, more students (46.5\%) stated a preference for Blackboard over Moodle, while $34.7 \%$ preferred Moodle, and nearly $20 \%$ had no preference. Factors that might explain these results are explored in some detail.

By and large, a basic utilisation is made of both platforms, as little more than electronic document repositories, in what Francis and Raftery, in 2005, designate as a Mode 1 level of engagement. We could, however, detect some instances of a more sophisticated Mode 2 utilisation, particularly with Moodle, underlining the role of faculty in integrating a sophisticated use of LMSs when designing their courses.
\end{abstract}

\section{The use of learning management systems (LMSs) in learning environments}

In recent years, we have witnessed the growing introduction of LMSs in all levels of schooling in Portugal. Establishments using LMSs are still a minority (a little above $25 \%$ of universities according to a study by DeltaConsultores, 2007), but this should evolve rapidly. The use of information technology (IT) in schools and universities has been strongly supported by the government through initiatives ranging from primary schools to higher education that have encouraged the acquisition of laptop computers for students and teachers under favourable conditions and secured broadband connections in all public establishments. Around 960000 laptop computers have been purchased by secondary school students and teachers, and about 370000 by primary schools (GCELPT, 2009). Students entering universities nowadays will already have their own laptop computer with an Internet connection, and a growing number will have used an LMS in school. 
Despite the increase in LMS adoption in schools and universities, concern has been expressed as to whether LMSs are being used as effective learning tools or merely as electronic document repositories (Badge, Cann \& Scott, 2005; Hall, 2006). Although there are some data on the overall adoption of LMSs in Portuguese schools and universities, very little is known as to how LMSs are used in practice. For example, we are yet to establish the extent to which this adoption is anywhere close to 'sustainable embedding', where e-learning is seen as 'an accepted and expected part of teaching and learning' (Nichols, 2008, p. 603).

Hall (2006) argues that successful implementations of LMSs depend, not only on providing training and support for instructors, but also on the level of student active engagement and student and instructor satisfaction with the LMS used. The user perspective is therefore crucial to examine the implementation of LMSs and to evaluate their success.

Francis and Raftery (2005, p. 2) distinguish among three e-learning modes of engagement, which correspond to growing levels of complexity and depth in LMS usage. Mode 1 is labelled 'baseline course administration and learner support', and illustrates situations where an LMS is used only 'to distribute course information and carry out course administration' and most learning activities occur in traditional classroom settings. In Mode 2, there is 'blended learning leading to significant enhancements to learning and teaching processes'. This mode entails combining face-to-face interaction with a more widespread use of features such as: communication tools promoting interaction between tutor and students or among students; collaboration tools that assist students in the development of group work and otherwise allow for the sharing of learning resources; assessment tools, including the submission of graded assignments, the completion of quiz tests and the provision of feedback on work submitted; and finally, the inclusion of learning content that allows each student to independently further their learning at their own pace and specific interest. The third mode corresponds to a fully-fledged 'online course/module' where most learning will take place using the LMS, with extensive use of the tools described above and only marginal face-to-face interaction.

These aspects affect the interpretation of data on LMS adoption. Nichols (2008) reveals considerable diversity among institutions in their progress towards e-learning sustainability. The fact that a learning platform is available, or that it is used extensively, does not necessarily mean they are used to similar levels of engagement. According to Hall (2006), most universities are at stage 1 of the Francis and Raftery (2005) model. Any comparison between alternative LMSs must also take into account the level of engagement to which they are being used.

In this paper, we seek to assess the extent and depth of the use of different LMSs in the University of Minho (Portugal). Our research question is 'Which are the perceptions and experiences of students in their use of Blackboard and Moodle?'

After reviewing previous studies that compare Blackboard and Moodle and explaining the University of Minho's setting, we describe our data collection process. We then present our results, subsequently discussing them and drawing conclusions that contribute to the research purpose stated above.

\section{Comparing Blackboard and Moodle}

One of the most popular LMSs in Portugal is Moodle, an open source platform that "educators can use to create effective online learning sites' (Moodle, n.d.). In 2007, it was used by $14 \%$ of Portuguese universities and most basic and secondary schools (DeltaConsultores, 2007). Moodle has actually become the standard LMS in public primary and secondary schools, and is encouraged by governmental projects.

Blackboard has preferentially targeted universities, being the world leading proprietary LMS. It is used by a few Portuguese higher education institutions. Apart from the University of Minho, it has been adopted by five other universities and some polytechnic institutes. 
Comparing these two LMSs is particularly interesting, not only because they are some of the more widely used platforms, but also because they present different features and functionalities that might be more or less adequate for different learning settings and objectives. Moreover, they represent quite different financial commitments to the institutions using them. We should not naïvely expect Moodle to be cost-free just because it is free to acquire and use. Administration and maintenance costs must be considered (Bremer \& Bryant, 2005). However, Blackboard is certainly much more expensive to maintain as it incurs a yearly cost of licensing. The benefits and risks of adopting an open-source platform vis-a-vis a commercial one have been explored elsewhere (Britain \& Liber, 1999). Evaluations of both Moodle (Gower \& Barr, 2005; Graf \& List, 2005) and Blackboard (Hall, 2006) on their own have also been produced exploring all the relevant technical issues.

However, there are not many studies directly comparing users' experience and evaluation of Moodle and Blackboard. Most such studies have been conducted within the growing number of universities across the world using Blackboard but considering open-source alternatives such as Moodle. On the whole, these studies seem to show a preference of users towards Moodle. Bremer and Bryant (2005) present results of a survey of 14 students, $80 \%$ of which state an overall preference for Moodle over Blackboard. In a study involving 84 education students in Hong Kong, Kennedy (2005) reports that 45\% of students preferred Moodle over Blackboard, although the majority (49\%) had no preference. Bos, Munoz and Van Duzer (2005) also show mixed results on their survey of 35 students. Moodle was favoured by students for its ability to promote interaction with fellow students and with the instructor; whereas, Blackboard was preferred in terms of the organisation of instructional materials. In the study by Machado and Tao (2007), however, course material organisation and communication were rated higher in Moodle than in Blackboard. The overall evaluation of the 53 students surveyed tended towards Moodle, $71 \%$ of them finding it easier to use than Blackboard and 75\% stating that they would prefer to use Moodle in the future as a replacement for Blackboard. In a recently published report by the University of Canterbury in New Zealand, of a study involving 750 respondents, $44.5 \%$ of the students judged Moodle to be better than Blackboard and 27.2\% preferred Blackboard; whereas, $26.9 \%$ stated no preference between them (University of Canterbury, 2008).

On the whole, these studies suggest students tend to prefer Moodle over Blackboard, although to varying degrees. As for more detailed explanations of students' preferences, these studies present more disparate and less comparable results. Moreover, other than the study by Canterbury University, they have been confined to rather limited student samples and focused primarily on students' perceptions and opinions of particular aspects of the platforms, making little if any connections with the overall impact of the LMSs on the enhancement of learning.

In this paper, we try to extend the comparison between Blackboard and Moodle in terms of their potential contribution to higher levels of student engagement.

\section{The use of LMSs in the University of Minho}

The University of Minho (UM) has pioneered the use of LMSs in Portugal. After an initial experiment with 'Easy', an in-house co-development with a Brazilian university, UM settled for Blackboard in 2006 (Microsoft, 2007). It has gradually been promoting Blackboard among faculty, providing training and technical support via its SAPIA service (SAPIA stands for Serviço de Apoio Informático à Aprendizagem, and translates to IT Support Service for Learning). The adoption of the Bologna Declaration principles prompted widespread discussion of new teaching and learning approaches and methods among faculty, accelerating the take-up of the LMS. Active learning, cooperative group work and autonomous student work are also encouraged methods. Intent on supporting them, UM implemented a wi-fi connection in its two campuses and promotes the generalised use of Blackboard. 
In parallel to the development of Easy and the purchase of Blackboard, many faculty members have begun to use Moodle on their own initiative as from about 2005. While Easy and Blackboard were at experimental stages, some departments (particularly in more technological areas) hosted Moodle instances within their Internet subdomains.

Additionally, increasing numbers of students coming to UM, where they encounter Blackboard, have experienced Moodle in secondary school. UM is therefore an ideal study ground for the comparison of Blackboard and Moodle because most students have used either one or both platforms roughly between the school years 2005-06 and 2008-09.

\section{Data collection}

We surveyed all the students enrolled in UM during the school year 2008-09 (around 15 000), both at undergraduate and at postgraduate levels. The survey comprised four parts: (1) identification, (2) level of experience, (3) features used, and (4) satisfaction with Moodle and Blackboard.

In the first section, biographical data was collected, as well as level and area of studies.

The second part covered students' level of experience with LMSs, including whether they had used LMSs in contexts other than UM (eg, in secondary school), and their self-perceived assessments of ease and frequency of use of both Moodle and Blackboard. The level of student satisfaction with LMSs has been shown to be affected, among other factors, by the level of computer skills and LMS experience (Drennan, Kennedy \& Pisarski, 2005). Ease of use has been argued to impact the acceptance of technology by students and, consequently, the success of LMS implementation. If the technology is perceived as being complex, it may pose as a distraction to the learning process (Brown, 2002). Ease of use has also been shown to be a strong predictor of perceived usefulness and intention to use (Hussein, Aditiawarman \& Mohamed, 2007). It also appears to be more important for recent users, the level of satisfaction of experienced users being less affected by ease of use (Drennan et al, 2005).

In the third part, students were asked about which features of Moodle and Blackboard they use most frequently. This seeks to assess the depth to which the LMSs are being used and the level of engagement of students.

In the final part of the survey, students were required to rate their satisfaction with Moodle and Blackboard on a number of features, including access to the platforms, organisation of course materials, navigation intuitiveness and communication tools. The degree to which they have felt the need to seek technical support was also queried.

The survey was administered electronically, using the Qualtrics survey software (Provo State: Utah Country: USA) (http://www.qualtrics.com). Invitations to reply were sent by email during the month of April 2009. We had 876 questionnaires submitted, which corresponds to a response rate of nearly $6 \%$. Although this rate is low, the size of our sample is very satisfactory, indeed the largest we have come across in studies comparing Blackboard and Moodle.

\section{Results and discussion}

\section{Overall description}

The large majority of students $(80 \%)$ are 18-27 years old, which fits the general age profile of undergraduate and master level students. The greater incidence of students between 19 and 23 $(51 \%)$ is explained by the proportion of undergraduate students in the sample $(72 \%)$. As for gender, $58 \%$ of the respondents were female, slightly over representing them in UM, where they account for $51.3 \%$ of students (student data for UM were collected from internal unpublished sources.). 


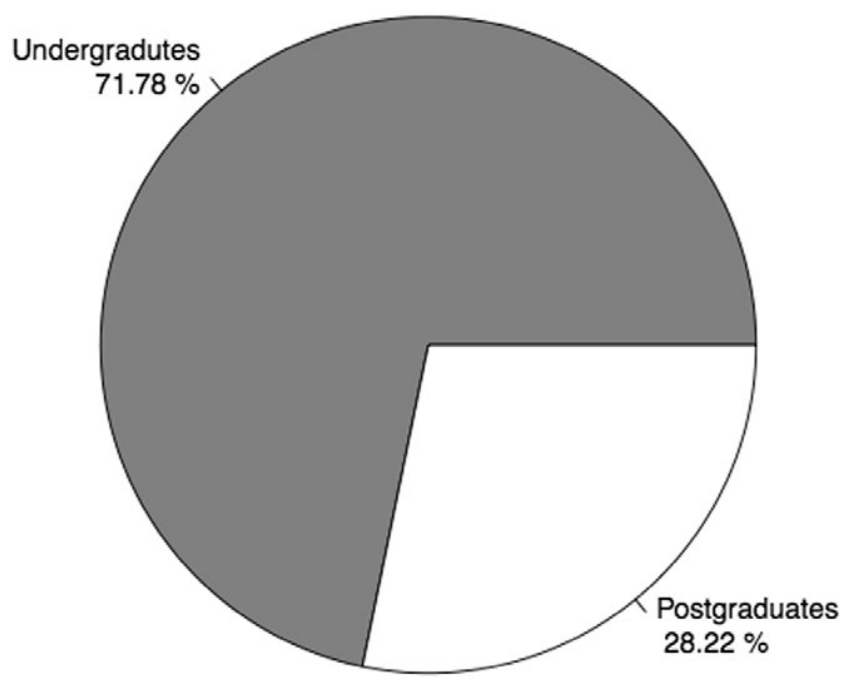

Figure 1: Distribution of students between Undergraduate and Postgraduate programmes.

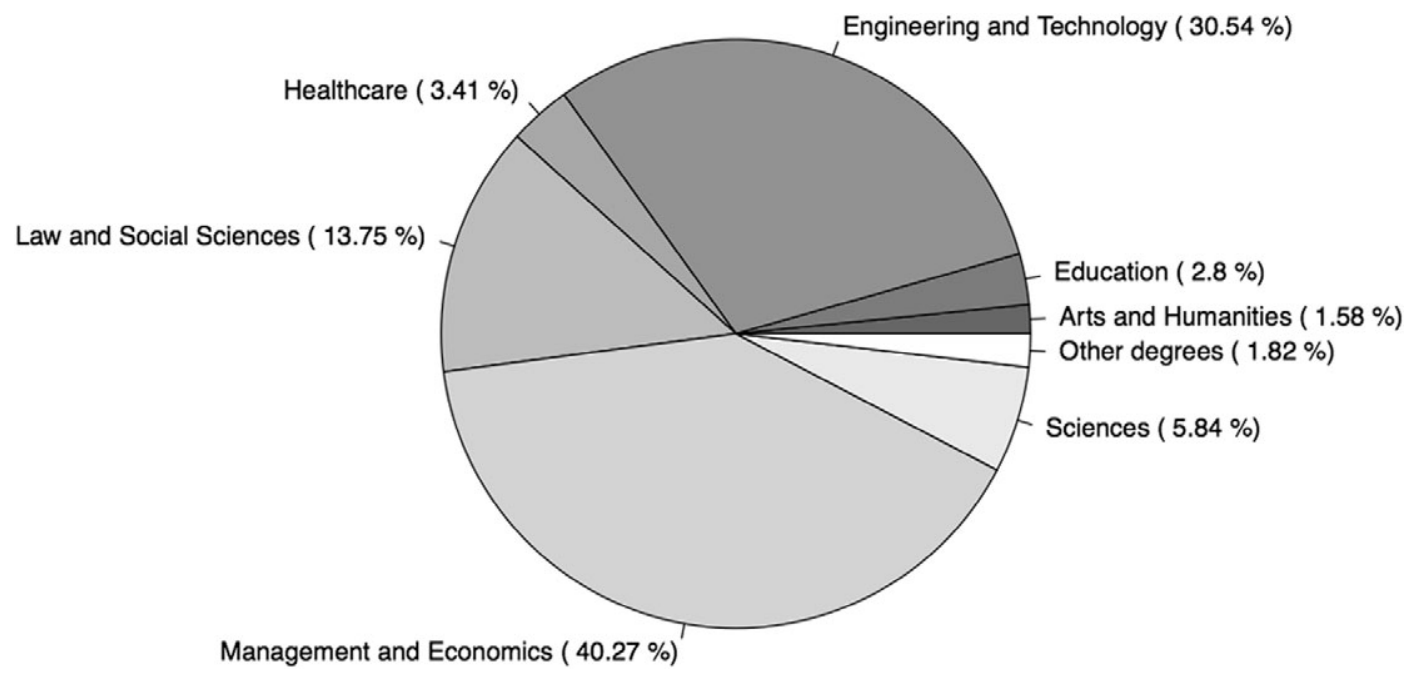

Figure 2: Distribution of students by study areas.

Nearly three quarters of the respondents (72\%) were undergraduates and $28 \%$ were postgraduate students attending Masters programmes (Figure 1). Postgraduates are also overrepresented as they make up for only $16.6 \%$ of UM students. Some of these attend courses given by the authors and may have been more predisposed to taking the survey than students with whom the authors were unfamiliar.

The same explanation might apply to the sample distribution among areas. Although all areas of learning are covered (Figure 2), the larger groups of students were in Management or Economics (40\%) or some kind of Engineering (31\%). In the overall UM distribution, only about 20\% of students attend Management and Economics programmes, and over 36\% are enrolled in Engineering. Law and Social Science students are also slightly overrepresented, with $14 \%$ against a University proportion of $11.7 \%$. On the contrary, Science students seem to be underrepresented ( $6 \%$ in the sample against $12 \%$ in UM), as are Arts and Humanities students $(2 \%$ in the sample 


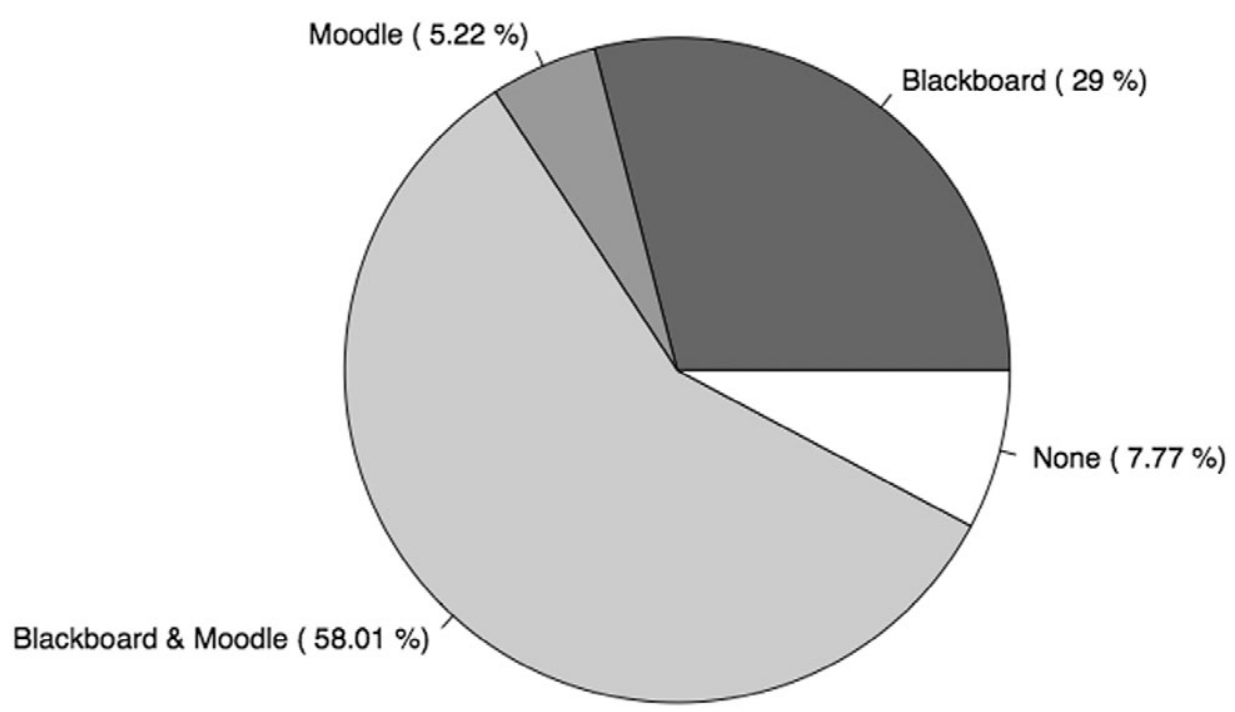

Figure 3: Distribution of students by LMS used.

against nearly $6 \%$ in UM), Education (3\% in the sample against $9.6 \%$ in UM) and Health Care students (3\% in the sample against $4.5 \%$ in UM).

Around $28 \%$ of all respondents had a 'student-worker' status, which means they might be less willing/able to come to classes and could benefit more from the distant learning functionalities of LMSs. Almost all students (98\%) declared to be reasonably, quite or very comfortable with using IT. This reflects the fact that students nowadays arrive at university with good technological skills. It could also indicate some degree of self-selection bias. Students that are less comfortable with IT might have refrained from responding.

The larger group of respondents (58\%) had used both Blackboard and Moodle, and 29\% had used only Blackboard. Only 5\% had used Moodle alone, and another $8 \%$ had used neither (Figure 3). These results may not be representative of all students in UM, as explained above. In this instance, we feel our own students (who will have used both Moodle and Blackboard) might have been more influenced to take the survey.

Few students had previous experience with these LMSs, with $88 \%$ of students using Blackboard and $76 \%$ of Moodle users never having used them before coming to UM. Those who had used Moodle had done so mostly in secondary school (10.8\%). A further 5.3\% encountered Moodle in another university, $3.7 \%$ in a professional training setting and $4.3 \%$ in other various contexts. Blackboard, on the other hand, had been previously used in other universities by $5.9 \%$ of students and, to a minor extent, in other settings (Figure 4).

A large proportion of students $(44.7 \%)$ declared that they did not use other collaborative platforms. Almost a quarter $(22.9 \%)$, however, use googlegroups, and $10.6 \%$ use yahoogroups. The most cited reasons for using these alternatives include 'my colleagues use it' (18.1\%), 'they have better functionalities for team work' (16.77\%), 'I already used it' (16.1\%) and, curiously, 'so that the instructor or other colleagues don't interfere in the team's work' (17\%). Also revealing is that $15.2 \%$ of students using alternative collaborative platforms do it because 'it's what the instructor uses in their course'. This means there are a number of faculty using alternative systems despite the fact that Blackboard is available to them. Perhaps they are not entirely satisfied with it, or they might be using these alternatives before, and are now unwilling to transfer to a new system. 


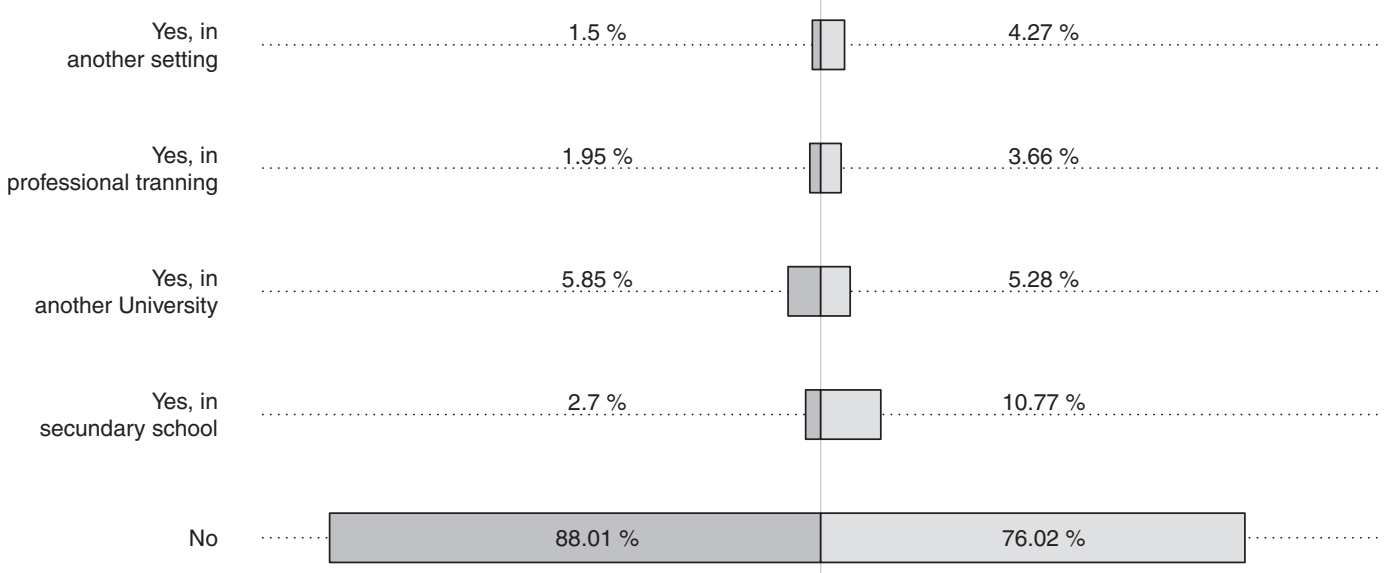

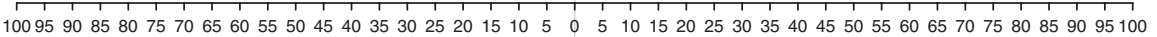

\section{Blackboard Moodle}

Figure 4: Previous experience of students with the LMSs: "Have you used Blackboard/Moodle before coming to UM?" (percentage of students in each situation).

\section{Levels of engagement}

As for the level of engagement to which the LMSs are used, as expected, the vast majority of students seem to experience no higher than Francis and Raftery's (2005) Mode 1. There is a very clear pattern whereby the frequency of use decreases as the LMS functionality becomes more 'engaging'. Figures 4 and 5 illustrate this most vividly.

Indeed, students using Blackboard (Figure 5) very often 'download course materials' (78.8\%), 'check course announcements' (63.4\%) and 'check course grades' (47\%); but most will only sometimes or rarely 'check the course syllabus and schedule' (36.7\% and 34.6\%, respectively) or 'submit assignments' (31.4\% and 28.5\%); nearly half have never used Blackboard to 'send emails to faculty or colleagues' (46\%) nor to 'take quiz tests' $(48.3 \%)$; and the vast majority have never engaged in 'participating in forum discussions' (72.4\%), 'sharing files with colleagues' $(74.2 \%)$ or 'participating in course chat-room or virtual classroom' $(89.9 \%)$.

Likewise, in their experience with Moodle (Figure 6), students tend to 'download course materials' $(67.2 \%)$, 'check course announcements' (47.5\%) more often than they 'submit assignments' ( $41 \%$ do it very often and $35.4 \%$ do it sometimes) and 'check course grades' (38.7\% very often; $34.5 \%$ sometimes). Most students will only 'check the course syllabus and schedule' (33.4\% sometimes; $40 \%$ rarely), 'take quiz tests' (26.5\% sometimes; $21.4 \%$ rarely) or 'check faculty and colleagues' contacts' ( $28 \%$ sometimes; $35.2 \%$ rarely) sometimes or rarely. Nearly half never 'send emails to faculty or colleagues' $(48.2 \%)$ or 'take course surveys' $(44.6 \%)$, and a greater proportion never engage in 'participating in forum discussions' $(60.4 \%)$, 'taking an online appointment with faculty' (60.8\%), 'sharing files with colleagues' $(73.9 \%)$ or 'participating in course chatroom or virtual classroom' $(86.7 \%)$.

Despite the same general trend, Moodle users more frequently use some of the more active features, such as submitting assignments and taking quiz tests. To test whether Moodle is being 


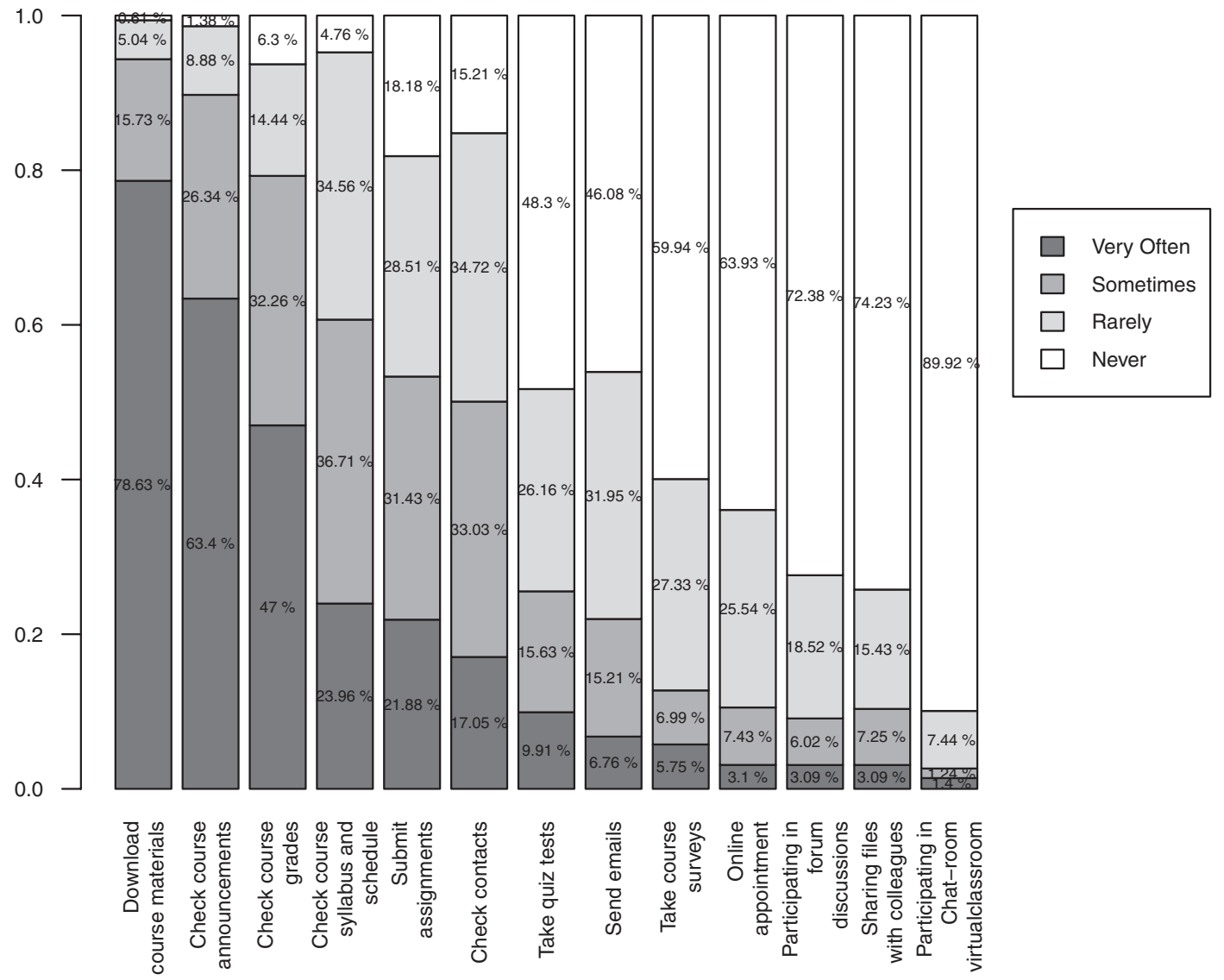

Figure 5: Frequency of use of different features in Blackboard.

used to a higher level of engagement than Blackboard, we checked for statistically significant differences between the means of the frequencies using the Mann-Whitney test, which is specifically indicated for analysing ranked ordinal type data and data that does not follow a normal distribution (Conover, 1980).

The results show (Table 1) that there are indeed statistically significant differences across most features. In a scale from 1 (very often) to 4 (never), students report being more involved in 'checking course announcements', 'checking the course syllabus and schedule', 'downloading course materials', 'checking course grades' and 'checking faculty and colleagues' contacts' when they are using Blackboard than when they use Moodle. Inversely, they are more likely to engage in 'submitting assignments', 'taking quiz tests', 'taking course surveys', and 'participating in forum discussions' or 'participating in course chat-room or virtual classroom' when they are using Moodle. It seems that, to some extent, the utilisation students make of Moodle encompasses higher engagement than that of Blackboard. This suggests that Moodle may be being utilised closer to Francis and Raftery's (2005) Mode 2 as students make more use of communication and collaboration tools.

The explanations we find for these differences are that Moodle is used willingly (indeed wilfully) by only a few faculty, most of which are in the Information Systems Department (ISD). These instructors may be more motivated and capable of using LMSs to a higher level of engagement. Blackboard, on the other hand, is being strongly encouraged among all faculty members, and a good part of them will use it only tentatively, exploring the more basic functionalities. 


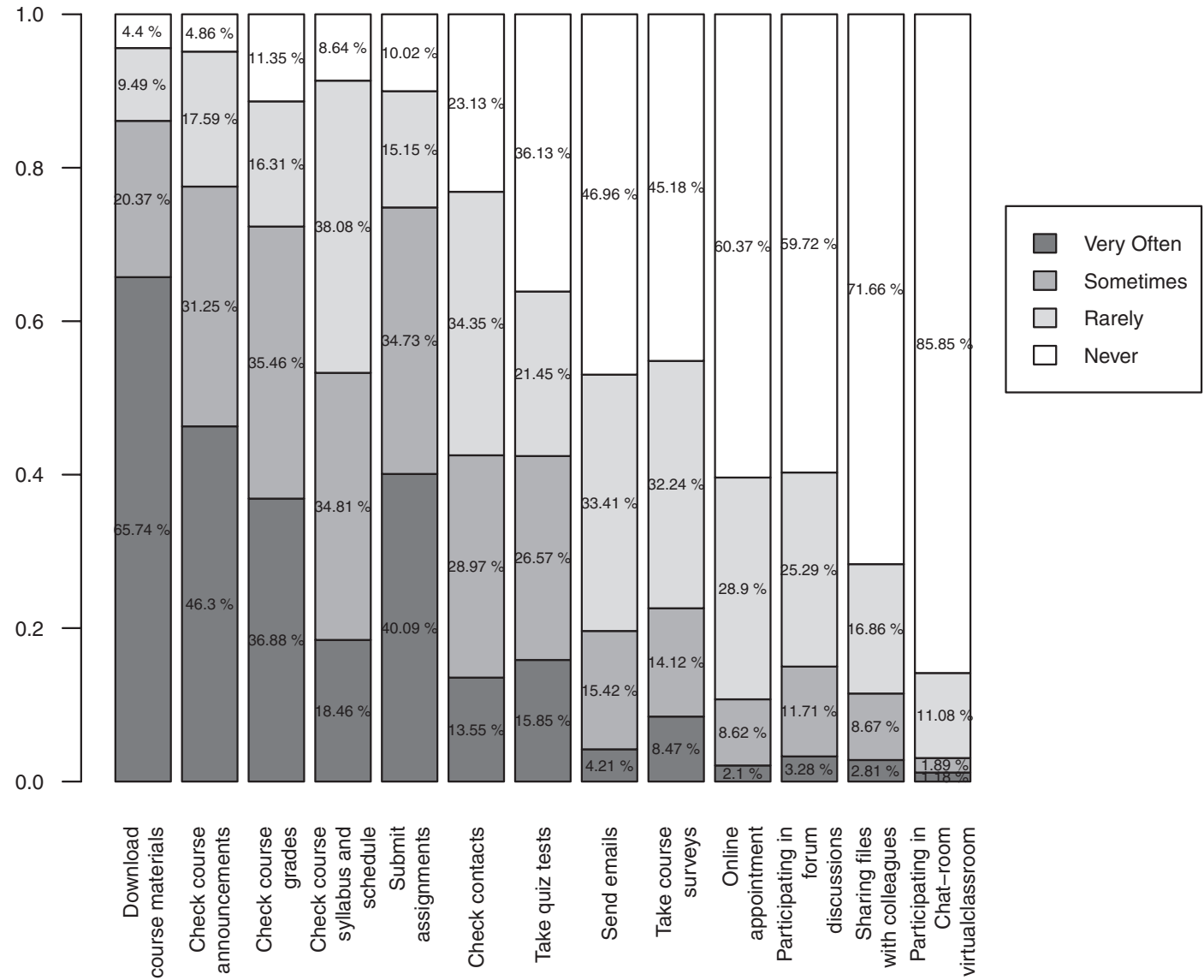

Figure 6: Frequency of use of different features in Moodle.

Table 1: Differences of frequency of use of functionalities in Blackboard and Moodle by all students (mean values of a 1 (very often) to 4 (never) frequency scale); Mann-Whitney test results: statistically significant differences $(p$-values $<5 \%)$ are signaled with $(*)$.

\begin{tabular}{lccc}
\hline & Blackboard & Moodle & P-value (\%) \\
\hline Download course materials (texts, activities, handouts) & 1.28 & 1.53 & $0.00^{*}$ \\
Check course announcements & 1.48 & 1.81 & $0.00^{*}$ \\
Check course grades & 1.80 & 2.02 & $0.03^{*}$ \\
Check the course syllabus and schedule & 2.20 & 2.37 & $0.29^{*}$ \\
Submit assignments & 2.43 & 1.95 & $0.00^{*}$ \\
Check faculty and colleagues' contacts & 2.48 & 2.67 & $0.17^{*}$ \\
Take quiz tests & 3.13 & 2.78 & $0.00^{*}$ \\
Send emails to faculty or colleagues & 3.17 & 3.23 & 48.12 \\
Take course surveys & 3.41 & 3.14 & $0.00^{*}$ \\
Taking an online appointment with faculty & 3.50 & 3.48 & 30.83 \\
Participating in forum discussions & 3.60 & 3.41 & $0.00^{*}$ \\
Sharing files with colleagues & 3.61 & 3.57 & 36.57 \\
Participating in course chat room or virtual classroom & 3.86 & 3.82 & 4.70 \\
\hline
\end{tabular}




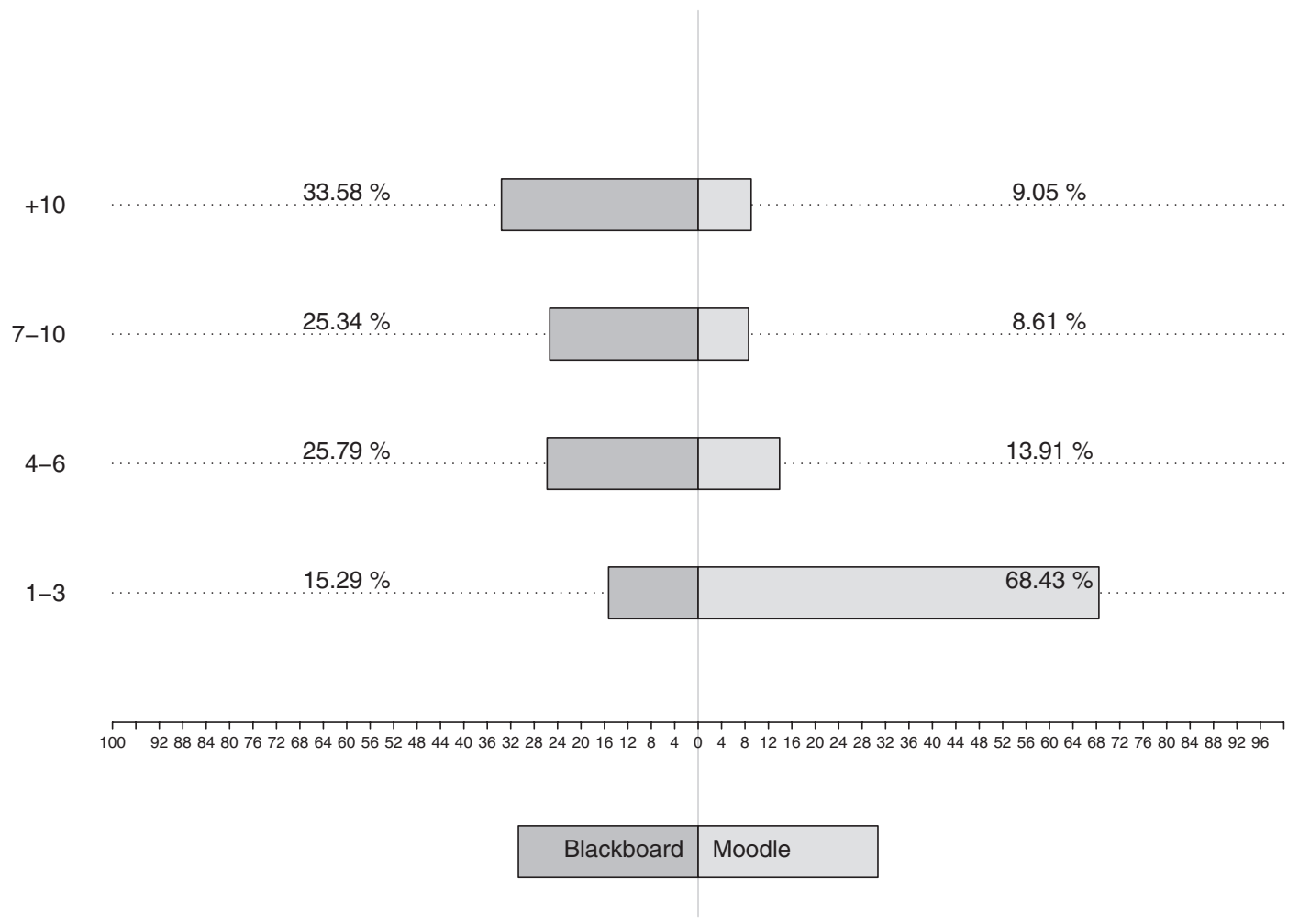

Figure 7: Number of courses accessed by students in each LMS.

Clearly, Mode 3, corresponding to fully fledged online learning, is far from being current in UM. This is reinforced by the fact that the vast majority (96\%) of students use the LMSs as a complement to the regular face-to-face classes, and only $4 \%$ claimed to use them as a substitute to classes. Although most of these (85.2\%) were student-workers, they represent only $12.5 \%$ of all student-workers. This supports the notion that the availability of an LMS is not sufficient for the development and successful operation of distance learning, as has been pointed out in literature (Mwanza \& Engeström, 2005).

We can therefore speak of what is called a 'blended learning' environment, with a generalised Mode 1 level of utilisation of LMSs, and some occasional instances of Mode 2.

Nevertheless, students seem to have incorporated the use of LMSs into their regular work routines. Most log on either everyday to Blackboard (46.7\%) and Moodle (31.5\%) or at least two to three times a week (36.9\% for Blackboard and 37.6\% for Moodle). Only 6.3\% of Blackboard users and $18.5 \%$ of Moodle users log on less than once a week.

Figure 7 shows the number of courses accessed by students in each LMS. Students using Blackboard access considerably more courses, with 33.6\% having more than 10 courses, 25.3\% having between seven and 10 and a further $25.8 \%$ having between four and six courses. Students using Moodle, on the other hand, access less than three for the most part (68.4\%); only 9\% have more than 10 courses available in Moodle. This is easily explained by the already mentioned situation whereby Moodle is used only marginally in UM, in ISD and by a few faculty members in the Management Department. Only students attending ISD programmes will use Moodle for more than a few courses. It also explains why Moodle users seem to log on less frequently. 


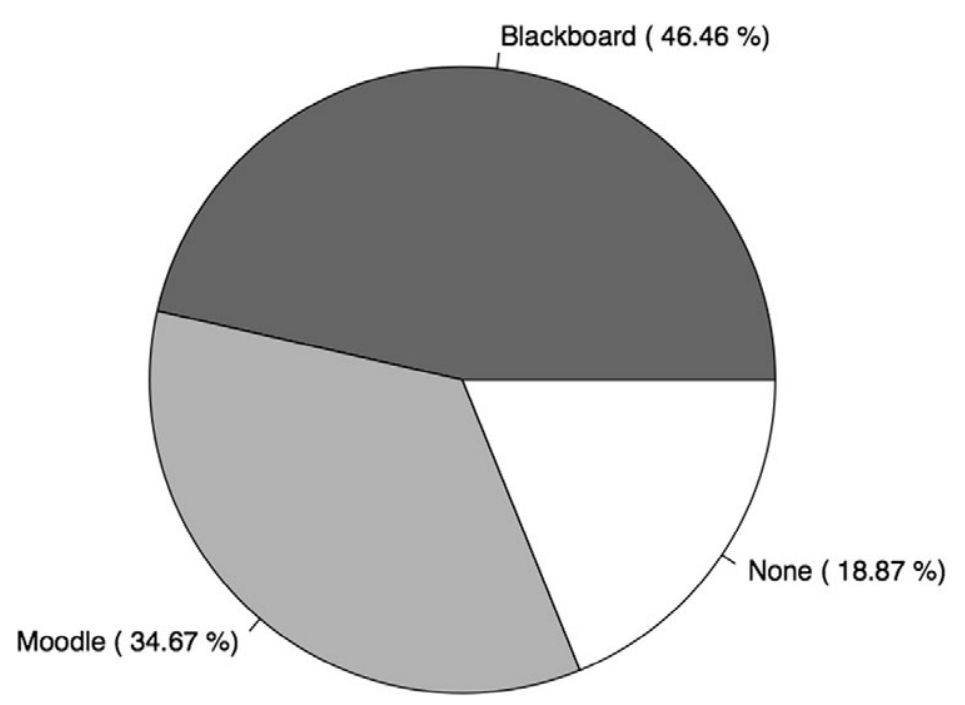

Figure 8: Student preference of LMS.

\section{Blackboard or Moodle?}

When asked directly (Figure 8 ), 46.5\% of the students with experience on both LMSs state a preference for Blackboard over Moodle; $34.7 \%$ prefer Moodle and 18.9\% have no preference. This contrasts with the previous studies comparing Blackboard and Moodle. As reviewed above, although to varying degrees, all studies reveal a student preference towards Moodle.

These results are also at odds with the evaluations students make of specific aspects of the LMSs (Figure 9). To identify the main beliefs students have about the two LMSs, we used a semanticdifferential scale, which is appropriated not only to describe the image individuals have about a subject, but also to compare the images of competing objects of study (Aaker, Kumar \& Day, 1998). Globally, students assess both systems positively, with the mean values generally above the scale middle-point of 3 (in a scale where 1 is worst and 5 is best). The best rated items in Blackboard are 'ease in logging in' and 'ease of access to materials'; whereas, in Moodle, they are 'ease in assignment submission' and 'ease of access to materials'. The worst aspects in both are 'participation in forums' and the 'search tool'. In both of these, there were a high percentage of neutral (scale middle-point) answers, which suggests students aren't quite able to evaluate these functionalities. Confronting this with the frequency of use of LMS features, participating in the course forum, or in the course chat room or virtual classroom, are indeed among the least used functionalities, which is consistent with the idea that LMS are used at the low levels of Francis and Raftery's (2005) modes of engagement.

In order to compare students' evaluations in a statistically relevant way, we again used a MannWhitney test to identify statistically significant differences between the means of the evaluations. Moodle is significantly better assessed in 'organization of materials', 'ease of access to materials' and 'participation in forums' (Table 2).

When considering only the students who use either Blackboard or Moodle, the single item where there is a statistically significant difference is the 'time required to learn the system', which is better assessed in Blackboard (mean = 3.68) than in Moodle (mean = 3.35). For students using both LMSs (Table 3), however, Moodle is significantly better rated in 'visual appearance' $($ mean $=3.75$ against mean $=3.60)$, 'intuitive navigation' $($ mean $=3.66$ against mean $=3.53$ ), 'ease of access to materials' (mean $=4.03$ against mean $=3.59$ ), 'participation in forums' 


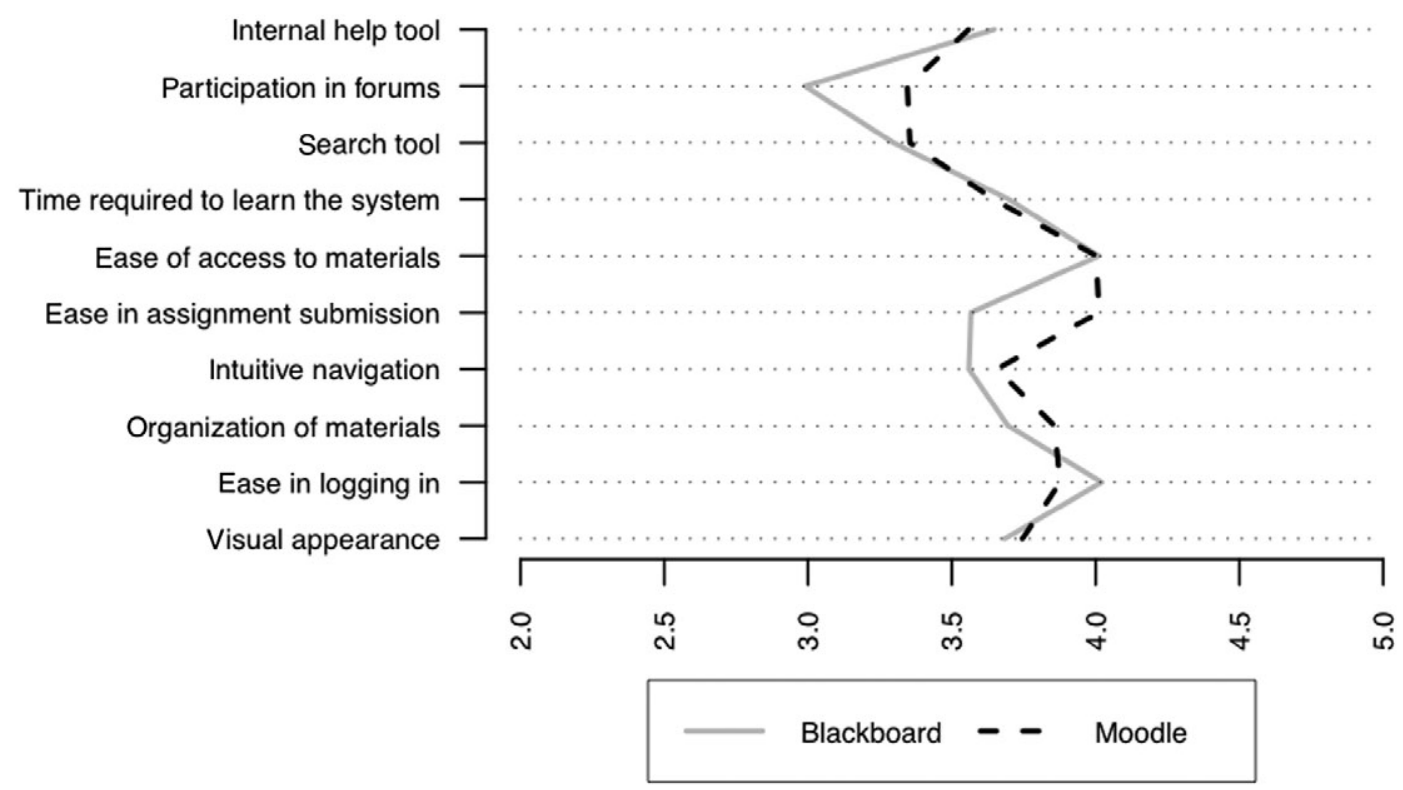

Figure 9: Student evaluations of Blackboard and Moodle across different features (mean values of a 1 (worst) to 5 (best) scale).

Table 2: Differences in evaluations of Blackboard and Moodle by all students (mean values of a 1 (worst) to 5 (best) scale); Mann-Whitney test results: statistically significant differences ( $p$-values $<5 \%$ ) are signaled with (*).

\begin{tabular}{lccc}
\hline & Blackboard & Moodle & P-value (\%) \\
\hline Ease in logging in & 4.02 & 3.88 & 5.56 \\
Ease in assignment submission & 4.01 & 4.00 & 70.37 \\
Time required to learn the system & 3.70 & 3.65 & 35.24 \\
Organisation of materials & 3.70 & 3.86 & $0.44^{*}$ \\
Visual appearance & 3.68 & 3.75 & 18.35 \\
Internal help tool & 3.65 & 3.56 & 14.24 \\
Ease of access to materials & 3.57 & 4.01 & $0.00^{*}$ \\
Intuitive navigation & 3.56 & 3.66 & 7.43 \\
Search tool & 3.30 & 3.35 & 53.88 \\
Participation in forums & 2.99 & 3.35 & $0.00^{*}$ \\
\hline
\end{tabular}

$($ mean $=3.35$ against mean $=2.95)$ and 'organization of materials' $($ mean $=3.88$ against mean = 3.67). Blackboard's evaluation is never better than Moodle's in this subsample. It appears, therefore, that when the students are able to compare Blackboard and Moodle, they find more advantages in Moodle than in Blackboard.

To explore this further, we used a multinomial logit regression, which is used to analyse if a set of predictor variables (numerical or categorical) can predict the probability of occurrence of a categorical event (for further details, please refer to Agresti (2002)). In this instance we tested if a set of variables (namely IT competence, area of study, previous use of Blackboard, previous use of Moodle, number of courses accessed in Blackboard and number of courses accessed in Moodle) influence student preference for either of the LSMs. The log likelihood ratio test showed that all of these variables are statistically relevant, as follows. 
Table 3: Differences in evaluations of Blackboard and Moodle only by students using both LMSs (mean values of a 1 (worst) to 5 (best) scale); Mann-Whitney test results: statistically significant differences (p-values $<5 \%)$ are signaled with $(*)$.

\begin{tabular}{lccc}
\hline & Blackboard & Moodle & p-value (\%) \\
\hline Ease in assignment submission & 3.99 & 4.02 & 32.06 \\
Ease in logging in & 3.97 & 3.88 & 38.35 \\
Time required to learn the system & 3.71 & 3.67 & 61.61 \\
Organisation of materials & 3.67 & 3.88 & $0.17^{*}$ \\
Visual appearance & 3.60 & 3.75 & $1.55^{*}$ \\
Ease of access to materials & 3.59 & 4.03 & $0.00^{*}$ \\
Internal help tool & 3.59 & 3.56 & 66.66 \\
Intuitive navigation & 3.53 & 3.66 & $2.99^{*}$ \\
Search tool & 3.24 & 3.35 & 18.20 \\
Participation in forums & 2.95 & 3.35 & $0.00^{*}$ \\
\hline
\end{tabular}

As for IT expertise, less competent students (not at all comfortable with IT) are nearly 5 times more likely than the very competent ones to prefer Moodle when all other variables are held constant (ie, they access the same number of courses, they have the same level of previous experience with the LMSs, etc.). Students declaring themselves to be quite comfortable with IT are more likely than students that are very comfortable not to have a preference (1.6 times more than preferring Blackboard and two times more than preferring Moodle).

Previous experience with LMSs also seems to affect students' preference. According to the logit regression, the odds of a student preferring Moodle over Blackboard is 1.21 times higher when they have used Moodle before (again, for students with the same IT competence, number of courses accessed, etc.). On the other hand, when students have used Blackboard before, they are nearly as likely (1.01 times) to prefer Blackboard than to prefer Moodle, and indeed slightly more disposed not to have a preference at all.

Moreover, the more students use one of the LMSs, the more they tend to prefer it. For example, students using Blackboard for 10 or more courses are 12 times more likely to prefer Blackboard than their colleagues accessing only one to three courses. When they use Moodle for 10 or more courses, they are 60 times more prone to choosing Moodle than when they use it for three courses or less. The odds of them having no preference also increase the more courses they access in each LMS. The fact that more students use Blackboard for more courses thus explains the overall preference for Blackboard. Adding to this, with Blackboard, students are registered by default by the university and use their standard UM login and password. In Moodle, however, they must be preregistered by their instructor, after which they need to request a password to the system that is sent to their email. If logging in to only a few courses requires them to use a different LMS with a different set of login and password, this may be felt as a nuisance, leading students to prefer Blackboard. Details such as this highlight the importance of institutional backup for the adoption and continued use of an LMS regardless of its inherent qualities.

Difficulties experienced by students

Students were also asked whether they experienced difficulties in using the LMSs, and what they were. Nearly half of the respondents had felt difficulties $(44.8 \%$ for Blackboard and $46.7 \%$ for Moodle). The most frequent problems (Figure 10) encountered by students using Blackboard were 'could not find the targeted material' and 'difficulties logging on to the system'. In Moodle, students mainly struggle with 'difficulties logging on to the system'; to a lesser extent they 'could not find the targeted material' or 'were not registered in the system'. A Pearson chi-square test 


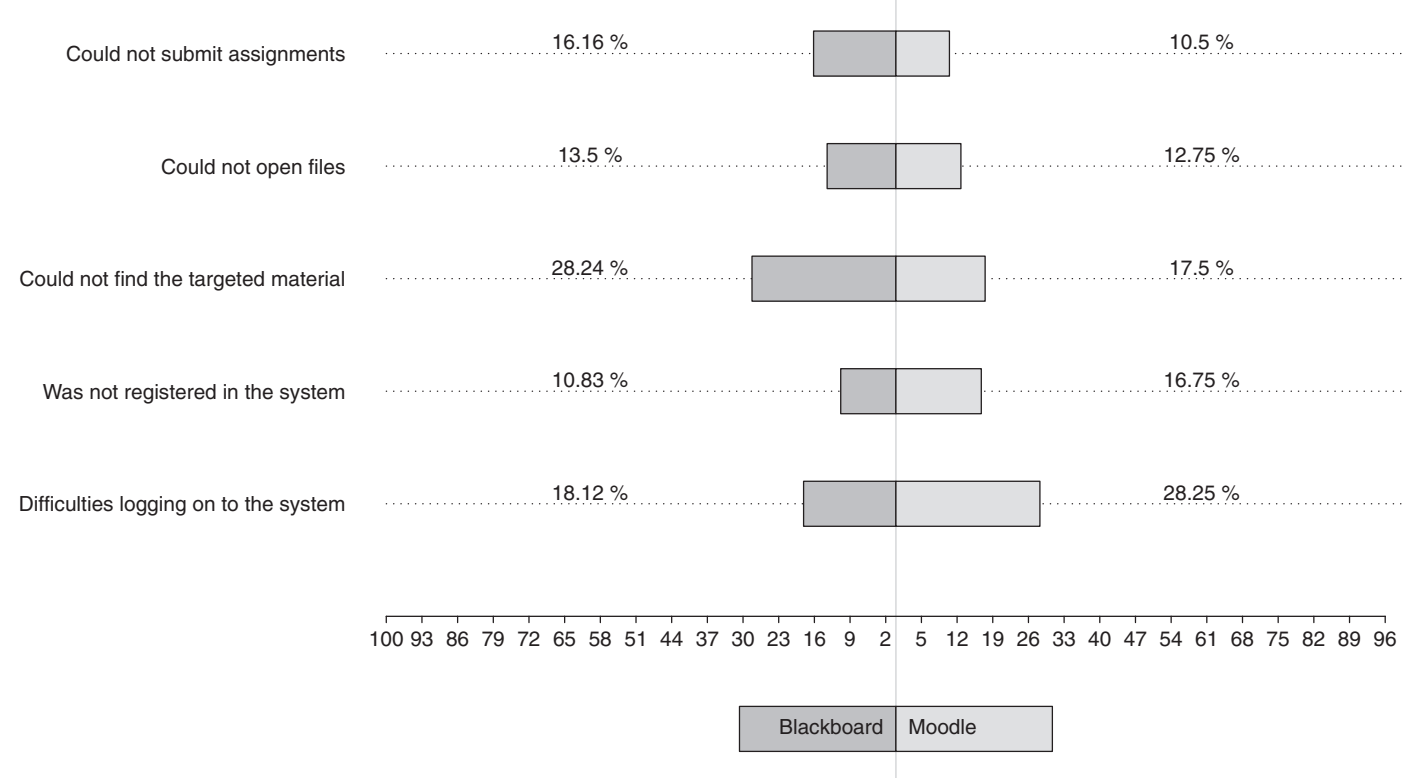

Figure 10: Difficulties felt by students with Blackboard and Moodle (percentage of students that felt each difficulty).

encountered the following difficulties to be felt more often in Blackboard than in Moodle, at a statistically significant level: 'could not submit assignments', 'could not open files', 'could not find the targeted material' and 'other difficulties'.

The results for Blackboard are not easily explained, because 'ease of access to materials' was one the best rated features in Blackboard. Clearly, this is a difficulty felt only by a limited number of students. The difficulties felt in logging on to Moodle, on the other hand, are reflected on the poor evaluation students make of that feature. As we have explained, students do have to follow a more complex procedure to register and log on to Moodle.

Logit regression analysis showed that the frequency of access is relevant in explaining how often students feel difficulties (controlling for the area and level of studies, IT competence, previous experience and frequency of access). Whichever the LMS, students logging on only once a week tend to have more difficulties than those accessing either more (everyday or two to three times a week) or less frequently (less than once a week). These latter users might be so occasional they don't encounter difficulties; whereas the more students use the platforms the more competent they become.

Having had previous experience with Moodle also makes students 1.68 times less likely to encounter difficulties sometimes, and 2.8 times less likely to experience them several times. With Blackboard, previous experience only makes students 1.07 times less prone to experience difficulties, suggesting students can become competent users of Moodle by using it more and more, but Blackboard could require greater effort.

Students were further asked whom they asked for help when they encountered problems (Figure 11). About 25\% in Blackboard and 22\% in Moodle did not look for any help. Most students using Blackboard turned to their colleagues for help, and next to faculty; whereas, Moodle users sought both faculty and colleagues alike. Only a minority of students using Moodle contacted SAPIA, and, more surprisingly, only $10.2 \%$ of Blackboard users seek SAPIA, who they know maintain Blackboard. 


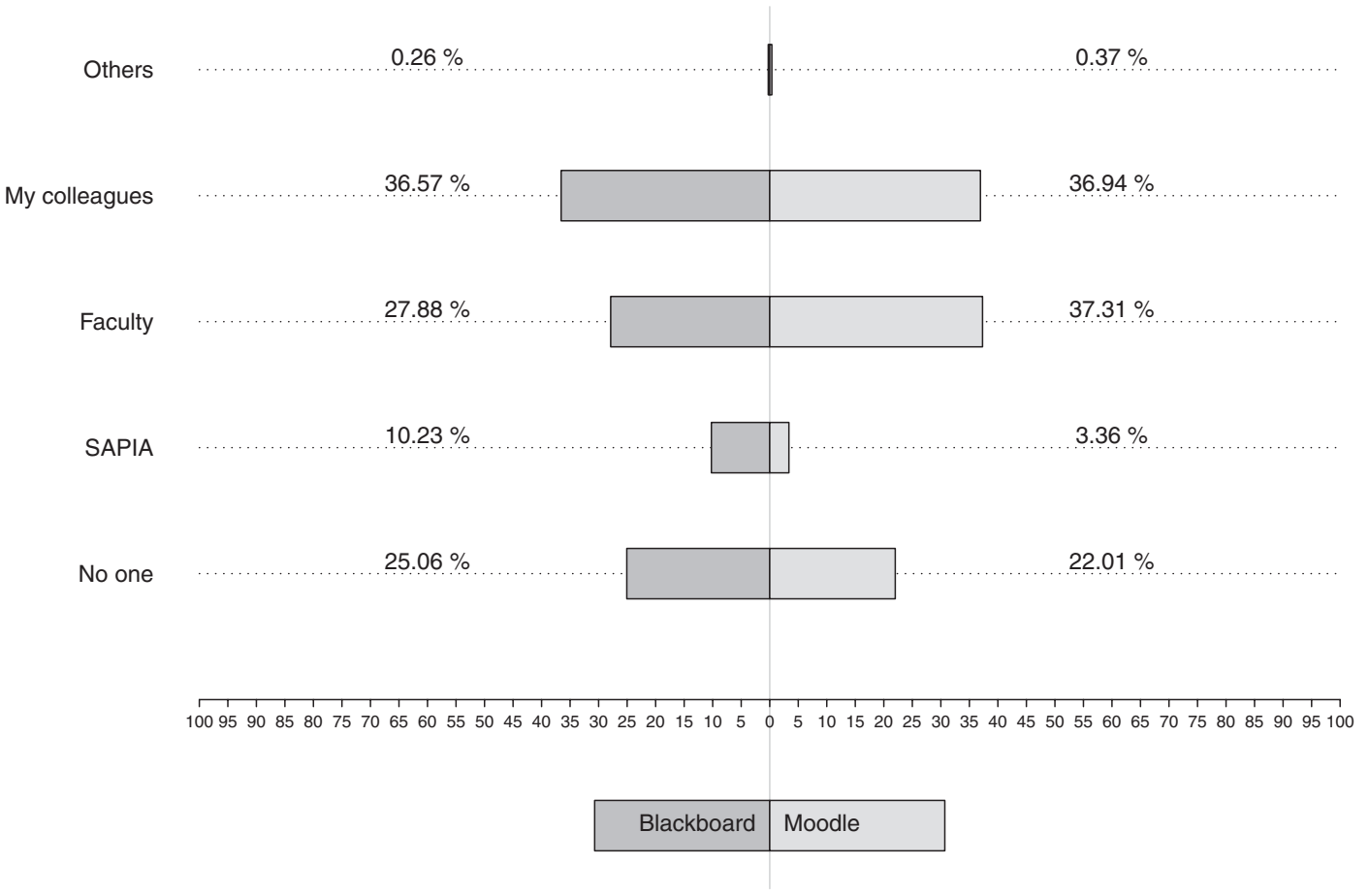

Figure 11: Help sought by students for Blackboard and Moodle (percentage of students seeking each kind of help).

Once again, we tested for the significance of these differences and found that to be the case with students not seeking any help and calling for SAPIA (more frequent with Blackboard), and looking to colleagues (more frequent with Moodle). This could indicate that a more cooperative environment might be encouraged among Moodle users.

\section{LMS impact on learning}

To assess student perceptions of the overall impact of using an LMS as a learning tool, we asked them to indicate their level of agreement with a set of statements using a Likert five-point scale. The statements (Table 4) covered aspects like how an LMS helped students with their learning, if it stimulated communication with faculty and among colleagues, whether students see them as a substitute or a complement for classes, and whether using them takes up a lot of time and effort. The results indicate an overall convergence of student perceptions in most items. Respondents tend to agree with most statements, with 'using an LMS helps me find the information I need', '... has a positive impact on my learning' and '... is not enough to pass the course' gathering the highest consensus. On the other hand, students disagree with the statements '... allows me not to attend classes' and '... takes up a lot of my time'. The statements towards which more students were indifferent (with a higher percentage on the scale middle-point) were '... helps with group work', '... helps communicating with faculty' and '... should be preceded by training sessions for students'.

On the whole, this indicates that students perceive LMSs to be beneficial to their learning activities, complementing rather than substituting classes. Although having an LMS available does not hinder group work and the communication with faculty, neither does it seem to enhance them. This could be linked to the level of engagement to which LMSs are being generally used. Operating 
Table 4: Student agreement with statements beginning with "Using an LMS..." (mean values of a 1 (totally disagree) to 5 (totally agree) agreement scale).

\begin{tabular}{|c|c|}
\hline & All respondents \\
\hline ... helps me find the information I need & 4.19 \\
\hline ... has a positive impact on my learning & 4.09 \\
\hline$\ldots$ is not enough to pass the course & 4.08 \\
\hline ... helps me keep up with the course work & 3.98 \\
\hline ... helps me organise my study & 3.78 \\
\hline ... serves mainly to download class Power Points & 3.52 \\
\hline ... helps me keep up when I miss a class & 3.48 \\
\hline ... helps with group work & 3.47 \\
\hline ... helps communicating with faculty & 3.41 \\
\hline ... should be preceded by training sessions for students & 3.17 \\
\hline ... takes up a lot of my time & 2.31 \\
\hline ... allows me not to attend classes & 1.78 \\
\hline
\end{tabular}

in a Mode 1 level of engagement is not enough to take advantage of all the LMSs potential, particularly when it comes to communication and collaboration activities.

\section{Conclusions}

LMSs are increasingly adopted in higher education. Blackboard and Moodle are two of the most commonly used LMSs in Portugal, and they are both used in the University of Minho (UM). Blackboard has been the institutionally adopted LMS since 2006, and Moodle has been informally used by a number of faculty since around 2005. Moodle is also the leading LMS in secondary schools in Portugal, which means most UM students will have contacted either one or both of these systems, providing an ideal setting for a comparative study.

This study surveyed students' perceptions and experiences with Blackboard and Moodle, including their level of satisfaction and mode of engagement, and their global preference of LMS and assessment of specific features and functionalities. Data were collected via an online survey distributed to all 15000 students enrolled in UM in 2008/09. Over 800 replies were submitted, representing a response rate of nearly $6 \%$. Although this is a large sample, the low rate of response is a limitation of this study, and we might be dealing with a largely self-selected sample.

Results show that most respondents are familiar with both Blackboard and Moodle (58\%). Nearly $30 \%$ use only Blackboard, the institutional LMS, but 5\% use only Moodle. A further $8 \%$ have used neither.

Overall, the students seem to appreciate the contribution of an LMS to their learning, viewing them as a complement rather than a substitute to classroom activities. However, the benefits gathered from using communication and collaboration tools to support group work could be improved, because students seem to find it hard to relate to these items.

Unlike previous studies directly comparing Blackboard and Moodle, the larger group of our students (46.5\%) state a preference for Blackboard, while $34.7 \%$ prefer Moodle. Nearly $20 \%$ have no preference. On the other hand, student assessment of LMS features (such as visual appearance, organisation of materials and intuitive navigation, etc.) tended to favour Moodle, and even more so when students were familiar with both systems and could directly compare them.

Logit regression analysis revealed that the number of courses accessed in each platform is pivotal. Students clearly tend to prefer the LMS that supports the greater number of their courses. Therefore, we suggest that logging on to Blackboard with the same login and password used for 
everything else in the university, and being able to access more courses in Blackboard, might be decisive advantages. Considering that the greater part of students state an overall preference for Blackboard despite evaluating Moodle better in specific features could indicate that having a single integrated LMS might be more important to them than which LMS they use. This underlines the importance of institutional support for the success of an LMS, as discussed by Nichols (2008).

Literature also identifies the level of expertise and experience with IT as affecting the satisfaction of students with LMSs (Drennan et al, 2005). In our sample, almost all students declared themselves to be at least reasonably comfortable with IT, but only few had previous experience with either Blackboard or Moodle. Still, those who did were more inclined to prefer the previously known LMS, especially in the case of Moodle. Less competent students, on the other hand, tended to prefer Moodle over Blackboard, and students that felt only moderately comfortable with IT were more likely not to have a preference. These questions would merit further qualitative exploration, either by interviewing students or organising focus groups, thus overcoming the limitations of a survey in terms of a deeper understanding of reality.

As for the level of engagement (Francis \& Raftery, 2005), our results confirm the expectations that, by and large, LMSs in UM are not used beyond Mode 1. The LMSs are used more as electronic document repositories than as active learning tools and students are much more likely to assume a passive role (ie, downloading class material or checking course announcements) rather than becoming active players (ie, sharing files with colleagues or participating in the course forum). There is, however, a hint that a Mode 2 level of utilisation is being ventured because a fair percentage of students claim to engage at least sometimes in activities such as submitting assignments and taking quiz tests. The fact that a vast majority of students claim to be at least reasonably comfortable with IT (98\%), and many use the LMSs daily (nearly 40\%), could suggest that they might be ready to use them to a higher mode of engagement. However, the level to which an LMS is used is, to a large extent, dependent on the way faculty manage their course and integrate LMSs in course activities. Our results show that the odd incidents of Mode 2 levels of engagement occurs more with Moodle than with Blackboard to a statistical significance, and we know that Moodle is adopted mainly by a few potentially more adept faculty members, which suggests that the mode of engagement here might be more dependent on the way faculty design and manage their courses than on the platform itself or on students' IT skills. Instructors' skills and motivation are decisive factors and, as Nichols (2008) points out, even where institutional culture, structure and systems are lacking, the initiative will fall on enthusiasts. Moreover, as Deepwell and Malik (2008) found out, students seem to rely strongly on their instructors' support, including guidance and feedback, and the students in our sample do turn to faculty for help.

If LMSs are to be used to higher levels of engagement in universities, positively contributing to enhancing student learning, faculty must be supported and encouraged to make better use of the technological tools available. Following the suggestion of Badge et al $(2005$, p. 6), the example and experience of those more enthusiastic and pioneering instructors could be 'harnessed to promote best practice' among their colleagues. Improving the use of LMSs in higher education may therefore be very much in the hands of faculty, whose perceptions and challenges should merit specific research. Comparing faculty perceptions with those of students would also give us a better insight into the level of satisfaction with LMSs of users in different roles.

\section{Acknowledgements}

We are grateful for the comments of three anonymous reviewers.

\section{References}

Aaker, D. A., Kumar, V. \& Day, G. S. (1998). Marketing research (6th ed.). New York: John Wiley \& Sons. Agresti, A. (2002). Categorical data analysis. Hoboken, NJ: John Wiley \& Sons. 
Badge, J. L., Cann, A. J. \& Scott, J. (2005). e-Learning versus e-teaching: seeing the pedagogic wood for the technological trees. Bioscience Education, 5. (May), Retrieved February 28, 2008, from http:// www.bioscience.heacademy.ac.uk/journal/vol5/beej-5-6.pdf

Bos, B., Munoz, K. D. \& Van Duzer, J. (2005). Blackboard vs. Moodle. A comparison of satisfaction with online teaching and learning tools, unpublished raw data. Retrieved February 28, 2008, from http:// users.humboldt.edu/joan/moodle/all.htm

Bremer, D. \& Bryant, R. (2005). A comparison of two learning management systems: Moodle vs Blackboard. In Proceedings of the 18th Annual Conference of the National Advisory Committee on Computing Qualifications (pp. 135-1390). Tauranga, New Zealand, July 11-13 2005.

Britain, S. \& Liber, O. (1999). A framework for the pedagogical evaluation of elearning environments. Bangor: University of Wales. Report \#41.

Brown, I. T. J. (2002). Individual and technological factors affecting perceived ease of use of web-based learning technologies in a developing country. Electronic Journal of Information Systems in Developing Countries, 9, 5, 1-15.

Conover, W. J. (1980). Practical nonparametric statistics (2nd ed.). New York: John Wiley \& Sons.

Deepwell, F. \& Malik, S. (2008). On campus, but out of class: an investigation into students' experiences of learning technologies in their self-directed study. ALT-J, 16, 1, 5-14.

DeltaConsultores (2007). Estudo das Plataformas de Formação à Distância em Portugal, Technical Report. Retrieved January 20, 2009, from http://www.elearning-pt.com/lms2

Drennan, J., Kennedy, J. \& Pisarski, A. (2005). Factors affecting student attitudes toward flexible online learning in management education. Journal of Educational Research, 98, 6, 331-338.

Francis, R. \& Raftery, J. (2005). Blended learning landscapes. Brookes eJournal of Learning and Teaching, 1, 3 , $1-5$.

GCELPT (Gabinete do Coordenador da Estratégia de Lisboa e do Plano Tecnológico) (2009). Relatório de Progresso do Plano Tecnológico. Retrieved July 20, 2009, from http://www.planotecnologico.pt

Gower, B. \& Barr, H. (2005). Tutor perceptions of the Moodle Learning Management System. Poster presented at the 22nd Annual Conference of ASCILITE, Brisbane, December 2005.

Graf, S. \& List, B. (2005). An evaluation of open source e-learning platforms stressing adaptation issues. ICALT 2005-Fifth IEEE International Conference on Advanced Learning Technologies, July 5-8, 2005, pp. $163-165$.

Hall, C. (2006). Lighting a fire or filling a pail? Users' perceptions of a virtual learning environment. Survey Report, University of Swansea. Retrieved February 28, 2008, from http://learninglab.swan.ac.uk/ Downloads/User_Survey_Report\%201.1.pdf

Hussein, R., Aditiawarman, U. \& Mohamed, N. (2007). E-learning acceptance in a developing country: a case of the indonesian open university. German e-Science Conference 2007, Baden-Baden, Germany, May $2-4,2007$.

Kennedy, D. M. (2005). Challenges in evaluating Hong Kong students' perceptions of Moodle. Proceedings of the 22nd Annual Conference of ASCILITE, Brisbane, December 2005.

Machado, M. \& Tao, E. (2007). Blackboard vs. Moodle: comparing user experience of learning management systems. 37th ASEE/IEEE Frontiers in Education Conference: global engineering: knowledge without borders, opportunities without passports, Milwaukee, WI, USA, October 10-13, 2007.

Microsoft (2007). Universidade do Minho responde aos desafios do e-Learning com plataforma Blackboard. Caso Prático Windows. Retrieved February 28, 2008, from http://www.microsoft.com/portugal/ obtenhafactos/casospraticos/uminho.mspx

Moodle (n.d.). Welcome to the Moodle community! Retrieved January 20, 2009, from http://moodle.org

Mwanza, D. \& Engeström, Y. (2005). Managing content in e-learning environments. British Journal of Educational Technology, 36, 3, 453-463.

Nichols, M. (2008). Institutional perspectives: the challenges of e-learning diffusion. British Journal of Educational Technology, 39, 4, 598-609.

University of Canterbury (2008). Final report of the LMS Review Steering Group - public version. Retrieved January 27, 2009, from http://uctl.canterbury.ac.nz/moodle/lms-review-process 